Provided for non-commercial research and education use. Not for reproduction, distribution or commercial use.

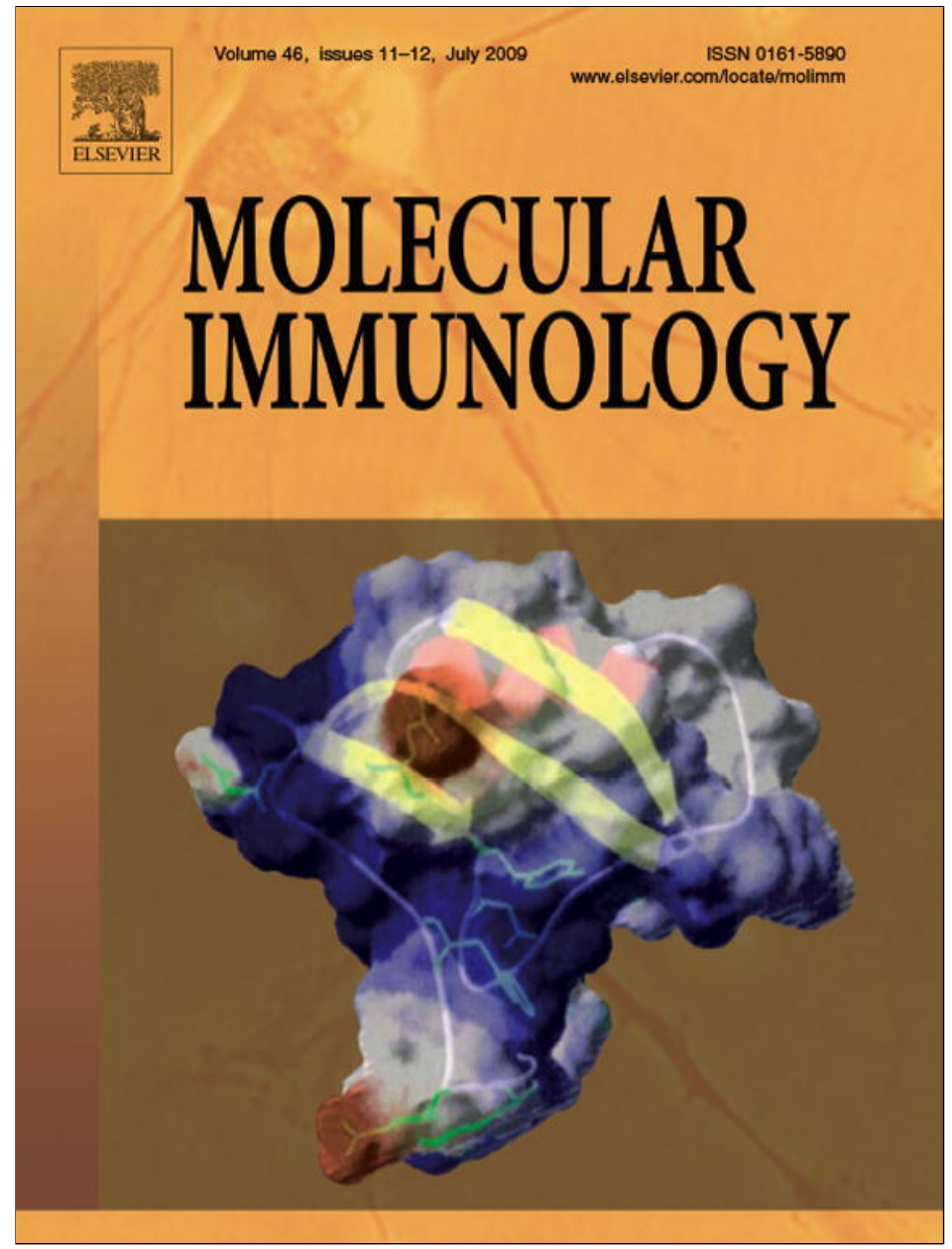

This article appeared in a journal published by Elsevier. The attached copy is furnished to the author for internal non-commercial research and education use, including for instruction at the authors institution and sharing with colleagues.

Other uses, including reproduction and distribution, or selling or licensing copies, or posting to personal, institutional or third party websites are prohibited.

In most cases authors are permitted to post their version of the article (e.g. in Word or Tex form) to their personal website or institutional repository. Authors requiring further information regarding Elsevier's archiving and manuscript policies are encouraged to visit:

http://www.elsevier.com/copyright 


\title{
Isolation and expression of a novel MBL-like collectin cDNA enhanced by LPS injection in the body wall of the ascidian Ciona intestinalis
}

\author{
Angela Bonura ${ }^{\mathrm{a}}$, Aiti Vizzini ${ }^{\mathrm{b}}$, Giuseppina Salerno ${ }^{\mathrm{b}}$, Nicolò Parrinello ${ }^{\mathrm{b}}$, \\ Valeria Longo ${ }^{a}$, Paolo Colombo ${ }^{\mathrm{a}, *}$ \\ a Istituto di Biomedicina ed Immunologia Molecolare “Alberto Monroy" del Consiglio Nazionale delle Ricerche, Via Ugo La Malfa 153, Palermo, Italy \\ ${ }^{\mathrm{b}}$ Dipartimento di Biologia Animale, Università di Palermo, Via Archirafi 18, Palermo, Italy
}

\section{A R T I C L E I N F O}

Article history:

Received 12 January 2009

Received in revised form 18 April 2009

Accepted 29 April 2009

\section{Keywords:}

Mannose-binding lectin

Innate immune system

LPS

Ciona intestinalis

\begin{abstract}
A B S T R A C T
Collectins are a family of calcium-dependent lectins that are characterized by their collagen-like domains. Considerable interest has been focused on this class of proteins because of their ability to interact with components of the complement system activating a cascade of events responsible for the activation of the innate immune system. A differential screening between LPS-challenged and naïve Ciona intestinalis has been performed allowing the isolation of a full length cDNA encoding for a $221 \mathrm{AA}$ protein. In silico analysis has shown that this polypeptide displays protein domains with similarities to mannose-binding lectins. A phylogenetic analysis suggested that $C$. intestinalis MBL has evolved early as a prototype of vertebrate MBL. Real-time PCR assay demonstrated that this gene is strongly activated after LPS injection in the tunica. In situ hybridization performed in LPS-induced animals has shown that this gene is expressed in granular amoebocytes and large granules hemocytes in the inflamed body wall tissue. Finally, an antimicrobial activity of the C. intestinalis MBL has been demonstrated.
\end{abstract}

(c) 2009 Elsevier Ltd. All rights reserved.
The innate immune system is the first defence level which enables the organisms to recognize foreign agents and destroy bacterial, fungal and viral pathogens through a variety of inducible effector mechanisms (Hoffmann et al., 1999). This level of immunity emerged early in the evolution, and the invertebrates have developed several defence responses including hemolymph coagulation, expression of antimicrobial peptides mediated by Toll-like receptors, and the lectin/complement pathway activated by bacterial cell wall components (Greenberg and Grinstein, 2002).

Lectins are proteins or glycoproteins contained in biological fluids and/or cells of plants, animals, bacteria, being also components of viruses (Sharon and Lis, 2001, 2004). They contain carbohydrate recognition domains (CRDs) forming structurally related protein families and superfamilies involved in several functions depending on protein-carbohydrate, protein-protein, protein-lipid or protein-nucleic acid interactions (Dodd and Drickamer, 2001; Kilpatrick, 2002; Vasta et al., 2004). In general terms, two main animal lectin types have been distinguished for some biochemical properties: $\mathrm{Ca}_{2}{ }^{+}$-dependent lectins (C-type) and $\mathrm{Ca}_{2}{ }^{+}$-independent lectins (S-type/galectins) (Dodd and Drickamer, 2001).

\footnotetext{
* Corresponding author at: Istituto di Biomedicina ed Immunologia Molecolare “Alberto Monroy", Via Ugo La Malfa 153, 90146 Palermo, Italy. Fax: +39 916809548. E-mail address: paolo.colombo@ibim.cnr.it (P. Colombo).
}

Vertebrate collectins, contained in the plasma and present on mucosal surface, are C-type lectins that recognize components of the Pathogen-Associated Molecular Patterns (PAMPS). In their basic functional structure, the collectins are trimers sharing a similar modular domain architecture. Each monomer consists of four regions: a cysteine-rich N-terminal domain (Hartshorn et al., 2002; Palaniyar et al., 2002), a collagenlike region (Arora et al., 2001; McCormack et al., 1997), an alpha-helical neck domain (Kishore et al., 1996) and a Cterminal carbohydrate recognition domain (CRD) (Weis et al., 1991).

Ascidians (subphylum Tunicata) are chordate invertebrates, closely related to vertebrates (Swalla et al., 2000), provided of innate immunity including allorecognition (Ben-Shlomo, 2008), inflammatory humoral and cellular responses (Parrinello, 1996; Parrinello et al., 1984a,b, 2007, 2003), and a lectin-dependent complement-like system (Pinto et al., 2003).

In the present paper, for the first time, we report on a Ciona intestinalis MBL-like lectin (CiMBL) cDNA which discloses a collagenous domain. In addition, we show that CiMBL gene is upregulated by LPS injection into the ascidian body wall. Sequence and Real-time PCR analyses as well as in situ hybridization assay reveal that LPS promptly induces CiMBL expression in granular amoebocytes and large granules hemocytes in the inflamed tissue. 


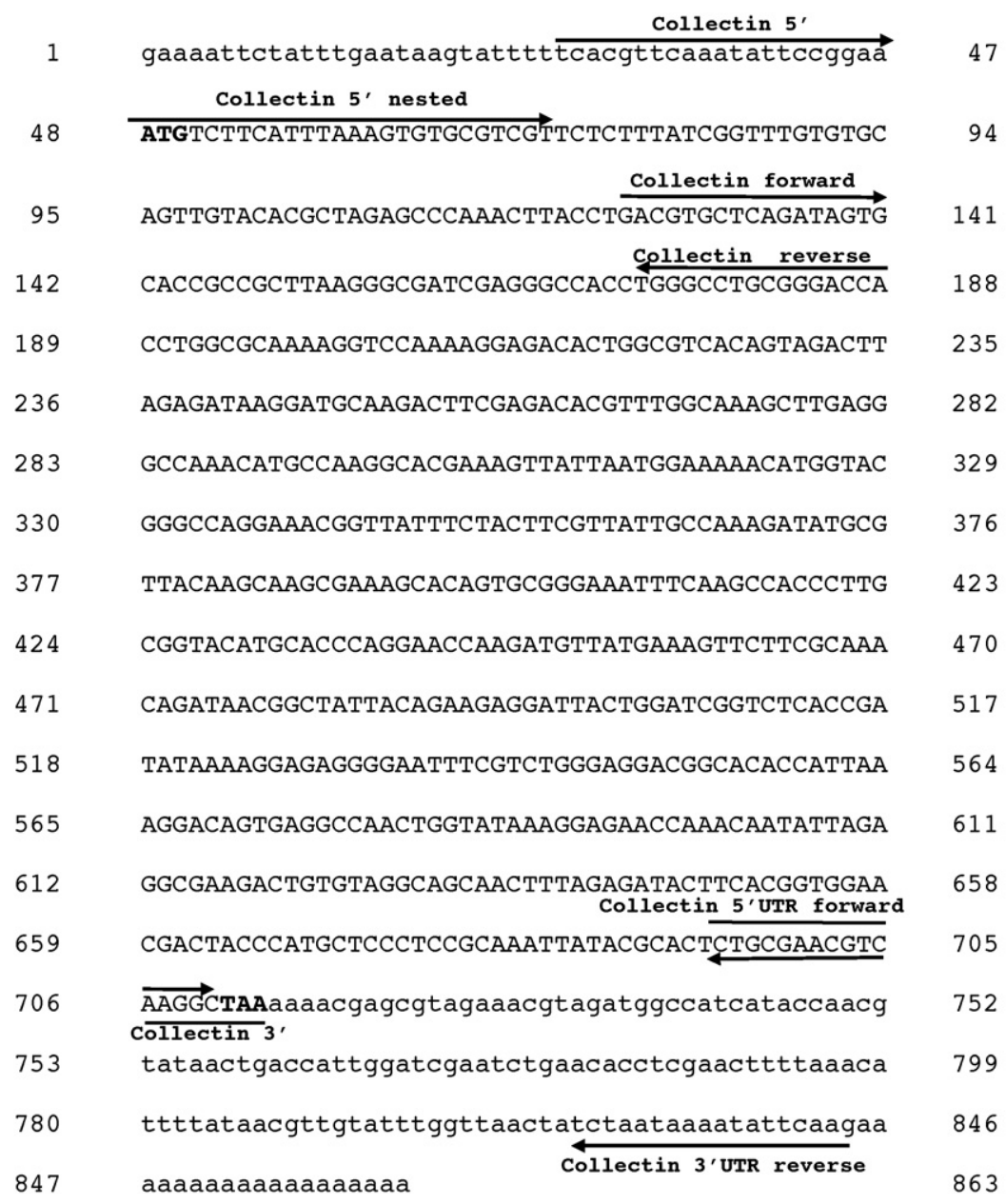

Fig. 1. Nucleotide sequence of the full length CiMBL cDNA. $5^{\prime}$ and $3^{\prime}$ untranslated regions are described in lower case letters. Upper case letters indicate the coding region with the first ATG and the stop codon highlighted in bold. The arrows indicate the oligonucleotide used for cloning procedures. The region from nucleotide 48 to nucleotide 713 is the coding region expressed from the inhibition assay (Collectin $5^{\prime}$ nested oligo vs Collectin $3^{\prime}$ oligo). The region from nucleotide 695 to nucleotide 844 is the probe used for the ISH assay (Collectin 5'UTR forward oligonucleotide vs Collectin 3'UTR reverse oligonucleotide).

\section{Materials and methods}

\subsection{LPS injection and RNA extraction}

Ascidians were collected from Sciacca Harbour (Sicily, Italy), maintained in tanks with aerated Sea Water at $15^{\circ} \mathrm{C}$, and fed every second day with a marine invertebrate diet coraliquid (Sera Heinsberg, Germany). Lipopolysaccharide (Escherichia coli 055:B5, LPS, Sigma-Aldrich, Germany) solution was prepared in sterile Sea Water $\left(12 \mathrm{mM} \mathrm{CaCl}_{2} \times 6 \mathrm{H}_{2} \mathrm{O}, 11 \mathrm{mM} \mathrm{KCl}, 26 \mathrm{mM} \mathrm{MgCl}_{2} \times 6 \mathrm{H}_{2} \mathrm{O}\right.$, $43 \mathrm{mM}$ Tris $\mathrm{HCl}, 0.4 \mathrm{M} \mathrm{NaCl}, \mathrm{pH} 8.0$ ). LPS solution (100 $\mu \mathrm{g}$ LPS in $100 \mu \mathrm{l}$ Sea Water per animal) was injected into the tunic tissue at the median body region. Untreated ascidians were used as controls.

Ascidian tissue fragments $(200 \mathrm{mg})$ explanted at various times (from 1 to $48 \mathrm{~h}$ ) were immediately soaked in RNAlater Tissue collection (Ambion, Austin, TX), and stored at $-80^{\circ} \mathrm{C}$. Total RNA extraction was performed by using an RNAqueous ${ }^{\mathrm{TM}}$-Midi Kit purification system (Ambion, Austin, TX). Poly $(A)^{+}$RNA was prepared from control and injected animals ( $1 \mathrm{~h}$ after injection) using Illustra ${ }^{\mathrm{TM}} \mathrm{mRNA}$ Purification Kit (GE Healthcare, UK) according to the manufacturer's instructions.

\subsection{Subtractive hybridization}

Subtractive hybridization was performed using the PCRSelect ${ }^{\mathrm{TM}}$ cDNA Subtraction Kit (Clontech Laboratories, USA) according to the manufacturer's instructions. This strategy is based on a PCR-based method for selective amplification of differentially expressed sequences allowing the isolation of transcript from activated tissues. Briefly, $2 \mathrm{mg}$ of poly $(\mathrm{A})^{+}$RNA from non-injected (driver) and injected (tester) animals were retrotranscribed. The tester and driver cDNAs were digested with the restriction enzyme Rsa I to yield blunt ends. The tester cDNA was then subdivided into two parts and each was ligated with a different cDNA adaptor (ADAPTOR 1: 5'-CTAATACGACTCACTATAGGGCTCGAGCGGCCGCCCGGGCAGGT-3'; ADAPTOR 2: 5'CTAATACGACTCACTATAGGGCAGCGTGGTCGCGGCCGAGGT-3'). The ends of the adaptor do not contain a phosphate group, so only one strand of each adaptor attaches to the $5^{\prime}$ ends of the cDNA. Two hybridizations were then performed. In the first run, an excess of driver was added to each sample of tester. The samples were then heat denatured and allowed to anneal. In the second run of hybridization, the two primary hybridization samples were mixed together without denaturing to allow the subtracted single strand tester cDNAs to re-associate. These new hybrids were molecules with different ends, which correspond to the sequences of the two adaptors. After filling in the ends by DNA polymerase, the differentially expressed sequences display different annealing sites for the nested primers on their $5^{\prime}$ and $3^{\prime}$ ends. The entire population of molecules is then subjected to PCR to amplify the desired differentially expressed sequences using the following primers (Nested PCR Primer 1 5'-TCGAGCGGCCGCCCGGGCAGGT-3'; Nested PCR Primer 
$25^{\prime}$-AGCGTGGTCGCGGCCGAGGT-3') and PCR conditions $\left(94^{\circ} \mathrm{C}\right.$ for $30^{\prime \prime}, 68^{\circ} \mathrm{C}$ for $30^{\prime \prime}, 72^{\circ} \mathrm{C}$ for $1,5^{\prime} ; 12$ cycles).

\subsection{Cloning and sequence analysis}

Differentially expressed cDNA were cloned in the pCR4-TOPO vector (Invitrogen, USA) and sequenced. Sequence analysis showed a cDNA fragment of 224 nucleotides. The full length sequence of the cDNA clone was obtained by using the GeneRacer kit (Invitrogen, USA). The kit ensures the amplification of only full length transcript via elimination of truncated messages from the amplification process. $5^{\prime}$ RACE was performed by PCR $\left(94^{\circ} \mathrm{C}\right.$ $1 \mathrm{~min}, 52^{\circ} \mathrm{C} 1 \mathrm{~min}, 72^{\circ} \mathrm{C} 1 \mathrm{~min}$ for 30 cycles) using the Collectin reverse-specific oligonucleotide (5'-TGGTCCCGCAGGCCCA- $3^{\prime}$ ) (see Fig. 1 for details) and the GeneRacer ${ }^{\mathrm{TM}} 5^{\prime}$-oligonucleotide (5'-CGACTGGAGCACGAGGACACTGA-3'). A nested PCR was performed using the GeneRacer ${ }^{\mathrm{TM}} 5^{\prime}$ nested-oligonucleotide $\left(5^{\prime}\right.$ GGACACTGACATGGACTGAAGGAGTA-3') and the Collectin reversespecific oligonucleotide described above.

$3^{\prime}$ RACE was performed using the Collectin 5 '-specific oligonucleotide (5'-TCACGTTCAAATATTCCGGAA-3') and the GeneRacer ${ }^{\mathrm{TM}}$ $3^{\prime}$ oligonucleotide (3'-GCAATGCATCGCATAGCAACTGTCG-5'). PCR products were re-amplified using the Collectin $5^{\prime}$ nested specific oligonucleotide ( $5^{\prime}$-ATGTCTTCATTTAAAGTGTGCGTCG-3') and the GeneRacer ${ }^{\mathrm{TM}} 3^{\prime}$ nested oligonucleotide (3'-GTGACAGTACGGCAATGCATCGC- $5^{\prime}$ ) (see Fig. 1 for details). Fragments were purified, ligated in the pCR4-TOPO vector (Invitrogen, USA) and sequenced.

\subsection{Sequence and phylogenetic analysis}

Similarity searches were performed using the FASTA program (http://www.ebi.ac.uk/Tools/fasta/) showing a high degree of homology to several mannose-binding lectins from vertebrate and invertebrate animals. Multiple alignments were accomplished with the Clustal W program (Thompson et al., 1994). A phylogenetic tree was constructed by the Neighbor-Joining method (NJ), and 1000 bootstrap replicates were performed.

\subsection{Real-time PCR analysis}

Tissue expression of the CiMBL gene was studied by Real-time PCR using the Taqman method. Primers and hybridization probes were designed using Primer Express software V.0 and synthesized commercially (Applied Biosystems, Foster City, USA). Real-time PCR analysis was performed using the Applied Biosystems 7500 Realtime PCR System, as described previously (Parrinello et al., 2008). Tissue expression was performed using CiMBL probe (CCTCCGCAAATTA).

CiMBL forward (5'-AGCCTTGACGTTCGCAGAGT-3') and reverse primers ( $5^{\prime}$-AGCCTTGACGTTCGCAGAGT- $3^{\prime}$ ), actin probe (accession number AJ297725), actin forward (5'-TGATGTTGCCGCACTCGTA -3') and reverse (5'-TCGACAATGGATCCGGT-3') primers. Each set of samples was run three times and each plate contained quadruplicate cDNA samples and negative controls.

The amplification efficiencies of the target and reference genes were approximately equal validating the $\Delta \Delta \mathrm{Ct}$ calculation. The amount of CiMBL transcript from different tissues was normalized to actin in order to compensate for variations in input RNA amounts. Relative CiMBL expression was determined by dividing the normalized value of the target gene in each tissue by the normalized value obtained from the untreated tissue.

\subsection{Body wall explant preparation and in situ hybridization assay}

The tunic surface was cleaned and sterilized with ethyl alcohol and body wall fragments ( $200 \mathrm{mg}$ ), containing both tunic and pharynx tissue, were excised from the injection site at various times after the injection (1-48 h).

For in situ hybridization (ISH) studies, body wall fragments were treated as previously described (REF). ISH was carried out with digoxigenin-11-UTP-labeled riboprobes $(1 \mu \mathrm{g} / \mathrm{ml}$ final concentration). The CiMBL probe was generated by PCR amplifying a cDNA fragment of 160 bp covering the $3^{\prime}$ untranslated region from nt 684 to nt 844 of the isolated cDNA using the Collectin $5^{\prime}$ UTR forward (5'-CTGCGAACGTCAAGGCT-3') and the Collectin 3'UTR reverse (5'CTTGAATATTTTATTAGA-3') oligonucleotides (see Fig. 1).

\subsection{Statistical methods}

Student's $t$-test was used to estimate statistical significance. Standard deviations were calculated based upon at least three experiments, each of them analyzed in triplicate. $P<0.01$ was considered statistically significant.

\section{Result}

\subsection{The CiMBL is a collagenous C-type lectin}

A PCR-based subtractive hybridization strategy allowed the isolation of a LPS-induced new form of collagenous lectin from the pharynx of $C$. intestinalis. 5' and 3' RACE was used to identify full length mRNAs and sequence analysis showed a $863 \mathrm{nn}$ cDNA with short 5' (47 nucleotides) and 3' (133 nucleotides) untranslated regions (see Fig. 1 for details) (Gene Bank accession number FJ595717). A BLAST search in Ensembl genome browser identified in the $C$. intestinalis genome a predicted gene (ID ENSCING00000014252), localized on Chromosome 12q: $956,317-958,035$. The cDNA codifies for a 221 AA protein with a deduced molecular weight of $24,484 \mathrm{Da}$ (Fig. 2). In particular, in silico analysis showed that the CiMBL contains a $\mathrm{NH}_{2}$ cysteinerich terminal domain capable of forming disulfide bridges between monomers to stabilize multimeric subunits and a type 2 collagen domain with a consensus sequence with $8 \mathrm{Gly}-\mathrm{X}-\mathrm{Y}$ repeats, where

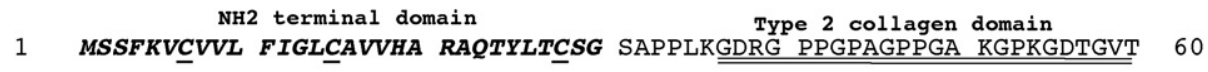 \\ 61 VDLEIRMQDF ETRLAKLEGQ TCQGTKVING KTWYGPGNGY FYFVIAKDMR YKQAKAQCGK 120 \\ neck region C-lectin domain (CRD) \\ 121 FQATLAVHAP RNQDVMKVLR KQITAITEED YWIGLTDIKG EGNFVWEDGT PLKDSEANWY 180 \\ Sugar specificity \\ 181 KGEP}

Fig. 2. cDNA deduced amino acid sequence of the CiMBL. Locations of putative structural domains were based on the Predict Protein algorithm. The $\mathrm{NH}_{2}$ terminal domain was indicated by italic bold letters. Double underlined amino acids indicate the $8 \mathrm{Gly}-\mathrm{X}-\mathrm{Y}$ collagenous repeats. The underlined amino acids indicate the alpha-helix domain. The bold amino acids indicate the C-lectin domain (CRD). The boxed amino acids in position 183-185 display the sugar specificity. The cysteine residues were underlined. 


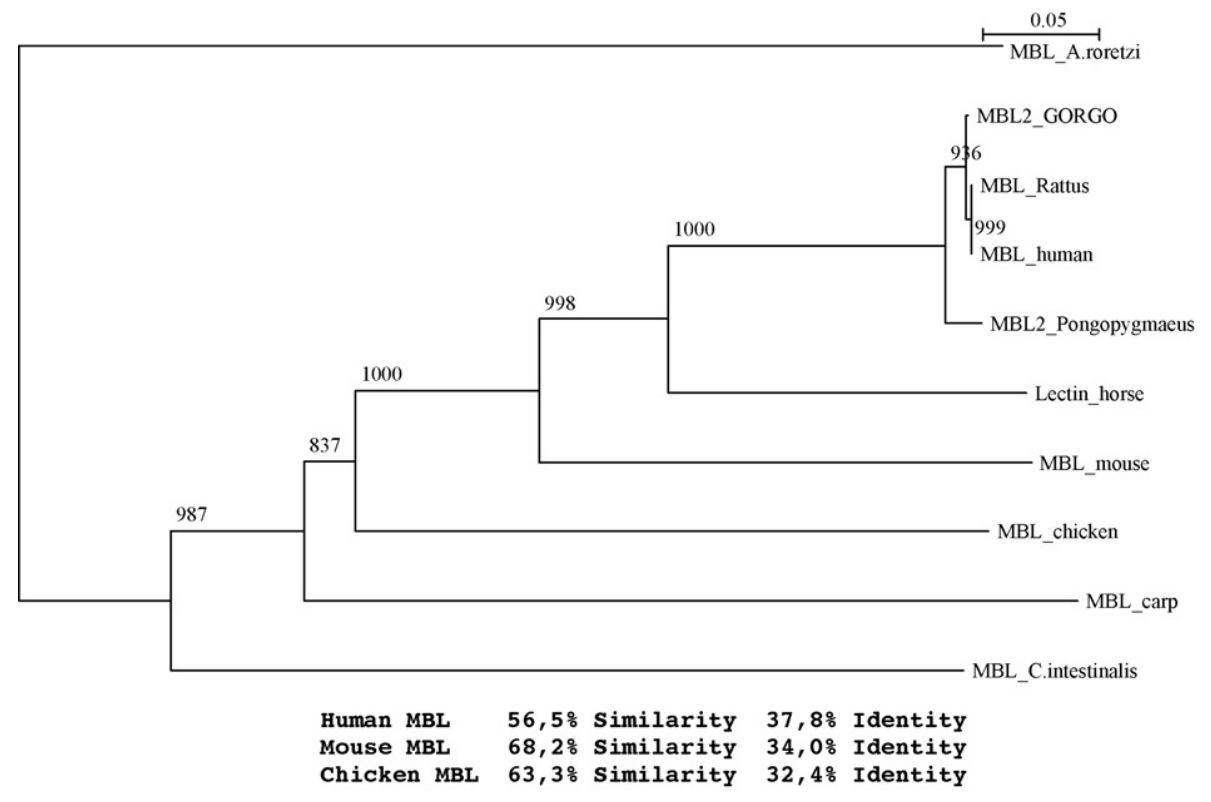

Fig. 3. Phylogenetic tree of CiMBL and MBL phylogenetic tree of vertebrate and invertebrate MBL family. The tree was constructed by the Neighbor-Joining method and bootstrap analysis. Numbers represent the percentages of 1000 bootstrap replicates in which the same internal branch was recovered. The horizontal bar indicates the number of nucleotide substitutions for site. The respective accession numbers are as follows: MBL Homo sapiens (CAB56124), MBL H. roretzi (BAB69891), MBL Chick (057451), MBL Horse (Q1WDE9), Bornean orangutan (Q66S64), Gorilla (Q66560), MBL Rattus (Q9Z294), MBL Carp (Q76BR8), MBL1_MOUSE (P39039). The bottom panel indicates the percentage of identity and similarity between human (CAB56124), Mus (Q9Z294) and Chick (057451) MBLs.

$\mathrm{X}$ and $\mathrm{Y}$ more frequently are prolines. In addition an alpha-helix domain between amino acids 110 and 145 has been identified. A Ctype lectin domain, also known as carbohydrate recognition domain (CRD), was found from amino acids 150-221. Finally, sequence analysis showed the presence of Glu183 and Asn185 residues that are highly conserved in CRDs that bind mannose/glucose (EPN type).

\subsection{Molecular phylogenetic analysis}

A EMBL Gene Bank comparison among vertebrate, invertebrate and the CiMBL deduced amino acid sequence was performed. Multiple alignments disclosed the following amino acid sequence similarity (SP) and identity percentages (IP): $56.5 \%$ SP and $37.8 \%$ IP with human MBL, $62.8 \%$ SP and 34.0\% IP with mouse MBL, 63.3\% SP and $32.4 \%$ IP with chicken MBL (Fig. 3).

The alignments generated a phylogenetic tree. The resulted alignment of vertebrate and invertebrate mannose-binding lectin (MBL) sequences shows that CiMBL forms a cluster with vertebrate MBLs as originated from a common ancestor gene. CiMBL sequence and Halocynthia roretzi MBL-like form separate clusters revealing that differences in carbohydrate recognition domain and in collagen-like domain can be found in the ascidian collectin-like molecules (Fig. 3).

\subsection{Quantitative mRNA expression analysis by Real-time PCR}

Quantitative mRNA expression in the inflamed pharynx excised from ascidians after in vivo LPS challenge, was examined by Real-time PCR analysis. The expression pattern, compared to a housekeeping gene, showed an enhanced level in CiMBL mRNA expression after stimulation. At each time point $(0,1,2,4,8,12$, $24,48 \mathrm{~h}$ ), the kinetic of gene expression was analyzed in 4 pharynx samples. The LPS injection up-regulated the gene activity, and CiMBL mRNA level was 6 -fold increased at $1 \mathrm{~h}$ after the injection, then decreased at 2 and $4 \mathrm{~h}$, and further increased in a gradual fashion within $24 \mathrm{~h}$ reaching its maximum peak of expression at $24 \mathrm{~h}$ (see Fig. 4).

\subsection{In situ hybridization}

In situ hybridization assay shows that CiMBL was expressed by hemocytes in the inflamed body wall tissue.

The histological transverse sections from naïve ascidians body wall showed a view of the tunic matrix, the epidermis lining the tunic, the connective tissue under the epidermis with lacunae of the open circulatory system, and the pharynx (Fig. 5). The tunic matrix presented scattered amoebocytes (Fig. 5, panel A); the epidermis monolayer lines the matrix and it was in contact with the connective tissue situated below and containing the longitudinal and circular muscles (Fig. 5, panels A and B). The inner part of the section showed the bars of the pharynx provided of vessels containing hemocytes with large granules (Fig. 5, panel C).At $1 \mathrm{~h}$ after the LPS inoculation, ISH analysis of histological sections disclosed that CiMBL mRNA was expressed by granular amoebocytes that infiltrated the inflamed tunic (Fig. 5, panel D), hemocytes with large granules contained in the lacunae (Fig. 5, panel E), in the pharynx bar vessels (Fig. 5, panel F), and scattered in the connective tissue lining the tunic. The CiMBL expressing hemocytes were more

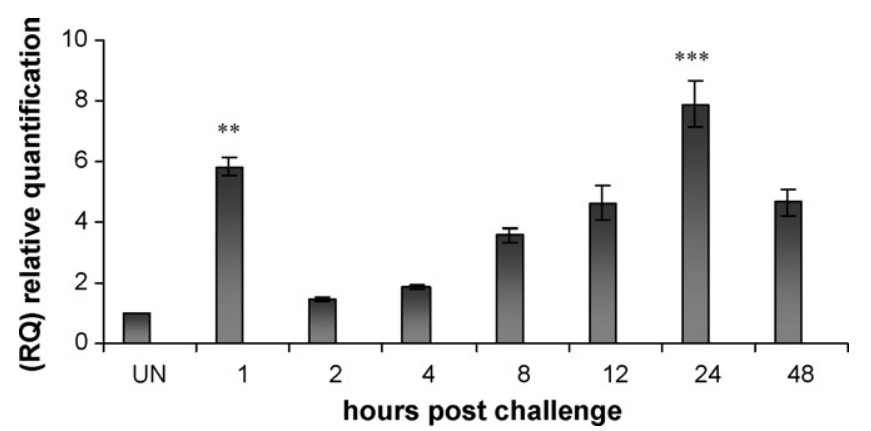

Fig. 4. Quantitative Real-time PCR. The plot describes the relative quantification of the induction of the CiMBL gene compared to an internal control. Numbers of the $X$-axis indicate the hours after injection of the animal with LPS and RNA sampling. The data on the $Y$-axis show the relative increase of the transcriptional activity. Significance was evaluated by comparing the values with the expression level of untreated pharynx from four ascidians. ${ }^{* *} P<0.01,{ }^{* * *} P<0.001$. 

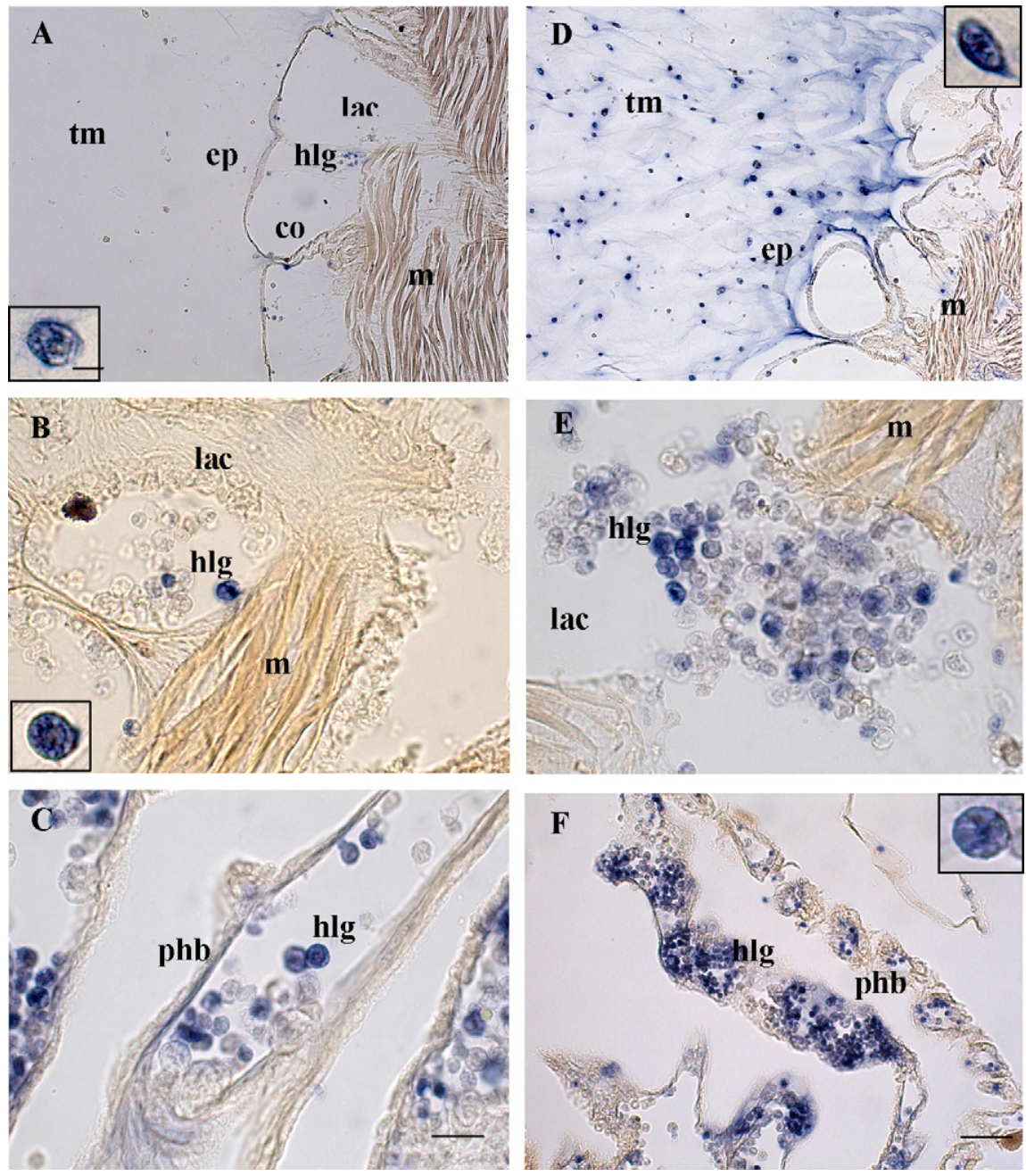

Fig. 5. In situ hybridization assay of body wall transverse sections of $C$. intestinalis. (A-C) Histological transverse sections from naïve ascidians. (A) Tunic matrix (tm), epidermis (ep) lining the tunic, connective tissue (co) under the epidermis with lacunae (lac) of the open circulatory system and muscles (m), hemocytes with large granules (hlg). Inset: Hemocyte with large granules. (B) Lacunae (lac) of the open circulatory system and muscles (m), hemocytes with large granules (hlg). Inset: Hemocyte with large granules. (C) Hemocyte with large granules (hlg), pharynx bars (phb) containing hemocytes. Bar: $100 \mu \mathrm{m}$. Inset bar: $10 \mu \mathrm{m}$. Body wall histological sections (D-F) from ascidians at $1 \mathrm{~h}$ after LPS inoculation. (D) Tunic matrix (tm); epidermis (ep) and muscles (m), inset: granular amebocyte. (E) Lacunae (lac) of the open circulatory system and muscles (m), hemocyte with large granules (hlg). (F) Pharynx bars (phb) and hemocyte with large granules (hlg). Inset: Hemocyte with large granules.

numerous in the body wall of the ascidians at $1 \mathrm{~h}$ after the LPS challenge, whereas they were rare in body wall sections from naïve ascidians.

\section{Discussion}

The invertebrates do not possess immunoglobulin-linked adaptive immune responses, and have developed several pathways to detect and respond to microbial surface antigens.

MBLs belong to the collectins family and, beside of complement activation (Petersen et al., 2001), exert several functions in host defence including agglutination (Schelenz et al., 1995), opsonization and activation of phagocytosis (Hajela et al., 2002), modulation of inflammatory response (Borron et al., 2000; Bufler et al., 2003) and inhibition of microbial growth (Wu et al., 2003).

Ascidian MBL-like lectin and ficolins have been identified as recognition molecules. The purified MBL-like lectin of $H$. roretzi binds specifically to glucose and has been designated as a glucosebinding lectin (GBL). Sequence analysis of GBL revealed that the C-terminal half contains a CRD homologous to C-type lectins, but the collagen-like domain was replaced by another sequence that has an $\alpha$-helix structure similar to the configuration of Gly-X-Y repeats (Sekine et al., 2001).
The inflammatory reaction in the tunic of $C$. intestinalis described for the first time by Parrinello et al. (1984a,b, 1990) is an intriguing model for the analysis of inducible host defence molecules. Recent reports showed that the injection of LPS induces the activation of several cellular and humoral components of the innate immune system (Cammarata et al., 2008; Parrinello et al., 2007, 2008; Vizzini et al., 2008).

In $C$. intestinalis genome, nine collectin-like genes have been identified. They appear to be transcriptionally active as shown by EST analysis (Azumi et al., 2003). In the present paper we show collectin gene expression in $C$. intestinalis inflammatory reaction challenged by LPS. A differential screening between LPS-challenged and naïve ascidians, allowed us to isolate a cDNA encoding a 221 AA protein (CiMBL) with $56.5 \%$ SP and $37.8 \%$ IP with human MBL, 62.8\% SP and 34.0\% IP with mouse MBL, 63.3\% SP and 32.4\% IP with chicken MBL. Sequence analysis also disclosed that the deduced CiMBL sequence presented a modular structure composed with a Ncysteine-rich terminal domain which could form disulfide bridges between monomers to stabilize multimeric subunits. Moreover, a type 2 collagen and an alpha-helix domain between the 110 and 145 amino acid positions, detected in other lectins, could be essential in the formation of collectin oligomers. Finally, a C-type CRD could recognize and bind to carbohydrates residues as a class of 
PAMPs commonly found on viruses, bacteria and fungi, that challenge immune responses. Sequence analysis of CiMBL CRD showed the presence of Glu183 and Asn 185 residues which are highly conserved in mannose/glucose-specific CRDs (EPN type). This sequence is crucial for the monosaccharide specificity since it has been shown that the replacement of Glu183 and Asn185 with Gln and Asp respectively (QPD type) modifies the sugar specificity (Drickamer, 1992).

As shown by the phylogenetic tree, CiMBL forms a cluster related to the vertebrate one suggesting that CiMBL evolved early as a prototype of vertebrate MBL. On the other hand, since CiMBL sequence and $H$. roretzi MBL-like form separate clusters it can be postulated that in ascidians many collectin-like molecules with different carbohydrate recognition domain and collagen-like domain, could represent products of gene duplication to expand variation of the innate immune system.

Real-time PCR analysis of pharynx tissues, showed that CiMBL gene expression is promptly modulated by LPS. At first, the induction was found at $1 \mathrm{~h}$, followed by a decrease after $2 \mathrm{~h}$, then the gene is re-activated and the CiMBL mRNA expression increased at $8 \mathrm{~h}$ reaching its maximum expression at $24 \mathrm{~h}$ after the LPS injection. Moreover, in situ hybridization revealed that LPS induces CiMBL expression in granular amoebocytes and large granules hemocytes in the inflamed body wall tissue.

In conclusion, the CiMBL here reported display properties of components of the innate immune system closely related to vertebrate MBLs. Its modular structure, with collagenous and carbohydrates recognition domains, and its pattern of expression suggest that it can be expressed in response to LPS in the inflammatory reaction of $C$. intestinalis initiating, presumably, the lectin branch of an ancestor complement pathway.

\section{References}

Arora, M., Munoz, E., Tenner, A.J., 2001. Identification of a site on mannanbinding lectin critical for enhancement of phagocytosis. J. Biol. Chem. 276 , 43087-43094.

Azumi, K., De Santis, R., De Tomaso, A., Rigoutsos, I., Yoshizaki, F., Pinto, M.R., Marino R., Shida, K., Ikeda, M., Ikeda, M., Arai, M., Inoue, Y., Shimizu, T., Satoh, N., Rokhsar, D.S., Du Pasquier, L., Kasahara, M., Satake, M., Nonaka, M., 2003. Genomic analysis of immunity in a Urochordate and the emergence of the vertebrate immune system: waiting for Godot. Immunogenetics 55, 570-581.

Ben-Shlomo, R., 2008. The molecular basis of allorecognition in ascidians. Bioessays 30, 1048-1051.

Borron, P., McIntosh, J.C., Korfhagen, T.R., Whitsett, J.A., Taylor, J., Wright, J.R., 2000 Surfactant-associated protein A inhibits LPS-induced cytokine and nitric oxide production in vivo. Am. J. Physiol. Lung Cell. Mol. Physiol. 278, L840-L847.

Bufler, P., Schmidt, B., Schikor, D., Bauernfeind, A., Crouch, E.C., Griese, M., 2003. Surfactant protein $A$ and $D$ differently regulate the immune response to nonmucoid Pseudomonas aeruginosa and its lipopolysaccharide. Am. J. Respir. Cell. Mol. Biol. 28, 249-256.

Cammarata, M., Arizza, V., Cianciolo, C., Parrinello, D., Vazzana, M., Vizzini, A. Salerno, G., Parrinello, N., 2008. The prophenoloxidase system is activated during the tunic inflammatory reaction of Ciona intestinalis. Cell Tissue Res. 333 481-492.

Dodd, R.B., Drickamer, K., 2001. Lectin-like proteins in model organisms: implications for evolution of carbohydrate-binding activity. Glycobiology 11, R71-R79.

Drickamer, K., 1992. Engineering galactose-binding activity into a C-type mannosebinding protein. Nature 360, 183-186.

Greenberg, S., Grinstein, S., 2002. Phagocytosis and innate immunity. Curr. Opin. Immunol. 14, 136-145.

Hajela, K., Kojima, M., Ambrus, G., Wong, K.H., Moffatt, B.E., Ferluga, J., Hajela, S., Gal, P., Sim, R.B., 2002. The biological functions of MBL-associated serine proteases (MASPs). Immunobiology 205, 467-475.

Hartshorn, K.L., White, M.R., Crouch, E.C., 2002. Contributions of the N- and C terminal domains of surfactant protein $d$ to the binding, aggregation, and phagocytic uptake of bacteria. Infect. Immun. 70, 6129-6139.
Hoffmann, J.A., Kafatos, F.C., Janeway, C.A., Ezekowitz, R.A., 1999. Phylogenetic perspectives in innate immunity. Science $284,1313-1318$.

Kilpatrick, D.C., 2002. Animal lectins: a historical introduction and overview. Biochim. Biophys. Acta 1572, 187-197.

Kishore, U., Wang, J.Y., Hoppe, H.J., Reid, K.B., 1996. The alpha-helical neck region of human lung surfactant protein $\mathrm{D}$ is essential for the binding of the carbohydrate recognition domains to lipopolysaccharides and phospholipids. Biochem. J. 318 (Pt 2), 505-511.

McCormack, F.X., Pattanajitvilai, S., Stewart, J., Possmayer, F., Inchley, K., Voelker, D.R., 1997. The Cys6 intermolecular disulfide bond and the collagen-like region of rat SP-A play critical roles in interactions with alveolar type II cells and surfactant lipids. J. Biol. Chem. 272, 27971-27979.

Palaniyar, N., Zhang, L., Kuzmenko, A., Ikegami, M., Wan, S., Wu, H., Korfhagen, T.R. Whitsett, J.A., McCormack, F.X., 2002. The role of pulmonary collectin N-terminal domains in surfactant structure, function, and homeostasis in vivo. J. Biol. Chem 277, 26971-26979.

Parrinello, N., 1996. Cytotoxic activity of tunicate hemocytes. Prog. Mol. Subcell. Biol. $15,190-217$

Parrinello, N., Patricolo, E. C.C., 1984a. Inflammatory-like reaction in the tunic of Ciona intestinalis (Tunicata). Encapsulation and tissue injury I. Biol. Bull. 167, 229-237.

Parrinello, N., Patricolo, E., C.C., 1984b. Inflammatory-like reaction in the tunic of Ciona intestinalis (Tunicata). Encapsulation tissue injury II. Biol. Bull. 167, 238-250.

Parrinello, N., Arizza, V., Cammarata, M., Giaramita, F.T., Pergolizzi, M., Vazzana, M. Vizzini, A., Parrinello, D., 2007. Inducible lectins with galectin properties and human IL1alpha epitopes opsonize yeast during the inflammatory response of the ascidian Ciona intestinalis. Cell Tissue Res. 329, 379-390.

Parrinello, N., Arizza, V., Chinnici, C., Parrinello, D., Cammarata, M., 2003. Phenoloxidases in ascidian hemocytes: characterization of the pro-phenoloxidase activating system. Comp. Biochem. Physiol. B Biochem. Mol. Biol. 135, 583-591.

Parrinello, N., De Leo, G., Di Bella, M.A., 1990. Fine structural observations of the granulocytes involved in the tunic inflammatory-like reaction of Ciona intestinalis (Tunicata). J. Invertebr. Pathol. 56, 181-189.

Parrinello, N., Vizzini, A., Arizza, V., Salerno, G., Parrinello, D., Cammarata, M., Giaramita, F.T., Vazzana, M., 2008. Enhanced expression of a cloned and sequenced Ciona intestinalis TNFalpha-like (CiTNF alpha) gene during the LPS-induced inflammatory response. Cell Tissue Res. 334, 305-317.

Petersen, S.V., Thiel, S., Jensenius, J.C., 2001. The mannan-binding lectin pathway of complement activation: biology and disease association. Mol. Immunol. 38 133-149.

Pinto, M.R., Chinnici, C.M., Kimura, Y., Melillo, D., Marino, R., Spruce, L.A., De Santis, R., Parrinello, N., Lambris, J.D., 2003. CiC3-1a-mediated chemotaxis in the deuterostome invertebrate Ciona intestinalis (Urochordata). J. Immunol. 171, 5521-5528.

Schelenz, S., Malhotra, R., Sim, R.B., Holmskov, U., Bancroft, G.J., 1995. Binding of host collectins to the pathogenic yeast Cryptococcus neoformans: human surfactant protein D acts as an agglutinin for acapsular yeast cells. Infect. Immun. 63 3360-3366

Sekine, H., Kenjo, A., Azumi, K., Ohi, G., Takahashi, M., Kasukawa, R., Ichikawa, N., Nakata, M., Mizuochi, T., Matsushita, M., Endo, Y., Fujita, T., 2001. An ancient lectin-dependent complement system in an ascidian: novel lectin isolated from the plasma of the solitary ascidian, Halocynthia roretzi. J. Immunol. 167, 4504-4510.

Sharon, N., Lis, H., 2001. The structural basis for carbohydrate recognition by lectins. Adv. Exp. Med. Biol. 491, 1-16.

Sharon, N., Lis, H., 2004. History of lectins: from hemagglutinins to biological recognition molecules. Glycobiology 14, 53R-62R.

Swalla, B.J., Cameron, C.B., Corley, L.S., Garey, J.R., 2000. Urochordates are monophyletic within the deuterostomes. Syst. Biol. 49, 52-64.

Thompson, J.D., Higgins, D.G., Gibson, T.J., 1994. CLUSTAL W: improving the sensitivity of progressive multiple sequence alignment through sequence weighting position-specific gap penalties and weight matrix choice. Nucleic Acids Res. 22, 4673-4680.

Vasta, G.R., Ahmed, H., Odom, E.W., 2004. Structural and functional diversity of lectin repertoires in invertebrates, protochordates and ectothermic vertebrates. Curr. Opin. Struct. Biol. 14, 617-630.

Vizzini, A., Pergolizzi, M., Vazzana, M., Salerno, G., Di Sano, C., Macaluso, P., Arizza, V. Parrinello, D., Cammarata, M., Parrinello, N., 2008. FACIT collagen (1alpha-chain) is expressed by hemocytes and epidermis during the inflammatory response of the ascidian Ciona intestinalis. Dev. Comp. Immunol. 32, 682-692

Weis, W.I., Crichlow, G.V., Murthy, H.M., Hendrickson, W.A., Drickamer, K., 1991. Physical characterization and crystallization of the carbohydrate-recognition domain of a mannose-binding protein from rat. J. Biol. Chem. 266, 20678-20686.

Wu, H., Kuzmenko, A., Wan, S., Schaffer, L., Weiss, A., Fisher, J.H., Kim, K.S., McCormack, F.X., 2003. Surfactant proteins A and D inhibit the growth of Gram-negative bacteria by increasing membrane permeability. J. Clin. Invest. 111, 1589-1602. 